\title{
Feasting, not fasting: winter diets of cave hibernating bats in the United States
}

\author{
Riley F. Bernard ${ }^{1,2,3^{*}} \mathbb{D}$, Emma V. Willcox², Reilly T. Jackson ${ }^{2,4}$, Veronica A. Brown ${ }^{5}$ and Gary F. McCracken ${ }^{3}$
}

\begin{abstract}
Temperate bat species use extended torpor to conserve energy when ambient temperatures are low and food resources are scarce. Previous research suggests that migratory bat species and species known to roost in thermally unstable locations, such as those that roost in trees, are more likely to remain active during winter. However, hibernating colonies of cave roosting bats in the southeastern United States may also be active and emerge from caves throughout the hibernation period. We report what bats are eating during these bouts of winter activity. We captured 2,044 bats of 10 species that emerged from six hibernacula over the course of 5 winters (October-April 2012/2013, 2013/2014, 2015/2016, 2016/2017, and 2017/2018). Using Next Generation sequencing of DNA from 284 fecal samples, we determined bats consumed at least 14 Orders of insect prey while active. Dietary composition did not vary among bat species; however, we did record variation in the dominant prey items represented in species' diets. We recorded Lepidoptera in the diet of $72.2 \%$ of individual Corynorhinus rafinesquii and $67.4 \%$ of individual Lasiurus borealis. Diptera were recorded in $32.4 \%$ of Myotis leibii, $37.4 \%$ of M. lucifugus, $35.5 \%$ of M. sodalis and $68.8 \%$ of Perimyotis subflavus. Our study is the first to use molecular genetic techniques to identify the winter diet of North American hibernating bats. The information from this study is integral to managing the landscape around bat hibernacula for insect prey, particularly in areas where hibernating bat populations are threatened by white-nose syndrome.
\end{abstract}

Keywords: Chiroptera, Foraging, Ion Torrent, Hibernation, Insects, MiSeq, Winter diet

\section{Introduction}

The low ambient temperatures experienced by temperate insectivorous bats during winter pose two energetic challenges. First, due to their small size and associated high surface area-to-volume ratio, cold winter conditions make bats susceptible to high levels of heat loss and energy expenditure [1-3]. Second, once expended, their energy reserves are not easily replenished, as prey availability in winter is limited as low ambient temperature reduces prey activity and abundance $[1,4-6]$. Therefore, temperate bats reduce their energetic costs in winter by engaging in periodic bouts of torpor, a physiological state

*Correspondence: rbernar5@uwyo.edu

1 Department of Zoology and Physiology, University of Wyoming, Laramie 82071, USA

Full list of author information is available at the end of the article characterized by low body temperature and metabolic rate, for prolonged periods of time $[1,7,8]$.

Due to the physiological constraints of hibernation, hibernating mammals, including temperate bats [9], must periodically arouse to maintain homeostasis, with typical activities being urination and drinking of water $[10,11]$. At higher temperate latitudes, where daily temperatures during winter rarely rise above freezing and there is little opportunity to feed due to scarcity of prey $[7,12,13]$, bats must survive on energy stored as fat and protein [2]. Under these conditions, arousals occur but are relatively infrequent [14-16]. In contrast, at lower latitudes where winters are milder, the hibernation season is shorter and prey abundance and activity are greater [17]. Therefore, winter foraging may provide bats the opportunity to replenish energy stores [2]. Periodic arousals and activity outside hibernacula during winter provide evidence for original author(s) and the source, provide a link to the Creative Commons licence, and indicate if changes were made. The images or other third party material in this article are included in the article's Creative Commons licence, unless indicated otherwise in a credit line to the material. If material is not included in the article's Creative Commons licence and your intended use is not permitted by statutory regulation or exceeds the permitted use, you will need to obtain permission directly from the copyright holder. To view a copy of this licence, visit http://creativecommons.org/licenses/by/4.0/. The Creative Commons Public Domain Dedication waiver (http://creativeco mmons.org/publicdomain/zero/1.0/) applies to the data made available in this article, unless otherwise stated in a credit line to the data. 
winter foraging both in North American and European bat species [7, 13, 18-24].

Although optimal hibernation theory [2] suggests that sporadic foraging can be advantageous for bats hibernating in milder temperate climates, it may become particularly important for North American cave-hibernating species suffering from the disease white-nose syndrome (WNS). Pseudogymnoascus destructans (Pd), the fungal agent that causes WNS, invades the cutaneous membrane of a bat's muzzle, wings, ears and tail membrane during hibernation, eroding the epidermis and underlying skin and connective tissue $[25,26]$. Once invasion occurs, the fungus disrupts torpor cycles and metabolic processes leading to the depletion of energy reserves through increased arousals, ultimately leading to increased morbidity and mortality during winter [27-29]. Pseudogymnoascus destructans was first detected in the southeastern United States (U.S.) in 2009, with WNS documented in Tennessee the winter of 2011 [30].

Foraging during intermittent arousals from hibernation may benefit bats at winter roost sites infected with $P d$ by augmenting energy reserves. In the southeastern U.S., bats remain active throughout winter regardless of $P d$ prevalence, with levels of activity corresponding to ambient temperature at dusk [31, 32]. As $P d$ became established in the southeastern U.S., daytime and cold temperature flights became more prevalent [31], yet less than $50 \%$ of the bats captured at these sites were positive for $P d$ and WNS, suggesting that winter activity was not driven by infection [33]. Although some active bats likely arouse throughout winter because of the physiological effects of WNS, many individuals with mild or no infection may be taking advantage of warm winter nights and higher prey availability to increase their energy reserves during hibernation. Therefore, it is important to determine what WNS susceptible bats are consuming during winter to better inform conservation actions implemented to help minimize disease related declines.

To date, the winter diet of North American bat species has been identified using traditional morphological methods [13, 18-20]. However, molecular methods, such as Next Generation sequencing of DNA amplified from fecal pellets, allow for a more complete view of the diet of insectivorous bats [34]. Although molecular techniques have been used to elucidate the diet of several insectivorous bat species [34-37], these studies have all been conducted during warm seasons. Our study is the first to examine the diet of North American insectivorous bat species captured outside of caves during winter. The rapid rates of digestion and defecation among bats [38] led us to infer that the fecal pellets provided by bats captured outside of hibernacula in winter (OctoberApril) would contain insect remains consumed during bouts of winter foraging. The objectives of our study were to (1) identify the dietary composition of bats captured throughout winter, (2) compare the composition of recently consumed prey among bat species, and (3) determine how the composition of each species' diet varied throughout the hibernation period (i.e., early-, mid-, and late-hibernation).

\section{Materials and methods \\ Study area}

During five winters (i.e., October-April of 2012/2013, 2013/2014, 2015/2016, 2016/2017, and 2017/2018), we collected fecal samples from bats captured at six hibernacula in middle and eastern Tennessee (Fig. 1). Two hibernacula in central Tennessee (Warren and White Caves) were located on the Cumberland Plateau, at 340-350 m elevation. Two northeastern hibernacula (Campbell and Hawkins Caves) were located within the Cumberland Mountains, both at approximately $450 \mathrm{~m}$ elevation. Blount Cave 1 and 2 were located in the Great Smoky Mountains National Park (GRSM) at 525 m elevation. Mean nightly winter temperatures outside hibernacula, measured from $30 \mathrm{~min}$ before dusk to $30 \mathrm{~min}$ after dawn using $\mathrm{HOBO} \mathrm{U}$-series data loggers (Onset Computer Corporation, Bourne, MA, USA), ranged from -2.03 to $20.16^{\circ} \mathrm{C}$.

\section{Bat captures}

We deployed single-, double- and triple-high mist nets (Avinet Inc., Dryden, NY, U.S.; mesh diameter: 75/2, $2.6 \mathrm{~m}$ high, 4-shelves, 6-12 $\mathrm{m}$ wide) at hibernacula entrances or across forest corridors within $100 \mathrm{~m}$ of hibernacula at least once per month from October April during each winter of the study. We opened mist nets $30 \mathrm{~min}$ before civil sunset and left them open for five hours, or until we captured 30 bats or ambient temperature dropped below $0{ }^{\circ} \mathrm{C}$. After capture, we placed bats in individual brown paper bags and held them for 30-60 min in an insulated box with four hand-warmers (HotHands ${ }^{\circledR}$, Dalton, GA, U.S.) to provide time for defecation. After holding, we identified each captured individual to species and determined sex, reproductive condition, forearm length $(\mathrm{mm})$, weight $(\mathrm{g})$, and wingdamage index (WDI, Reichard and Kunz 2009). We collected fecal pellets from the paper bags using sterile tweezers. We stored fecal pellets in $2.0 \mathrm{ml}$ microcentrifuge tubes (Fisherbrand ${ }^{\circledR}$, Fisher Scientific Co. L.L.C, Pittsburgh, PA, U.S.) with indicating silica gel desiccant (Grade 48, 4-10 mesh; Fisherbrand $^{\circledR}$, Fisher Scientific Co. L.L.C, Pittsburgh, PA, U.S.; [39]). Samples were frozen at $-20^{\circ} \mathrm{C}$ the night of collection and stored until analysis.

Field research followed U.S. Fish and Wildlife Services (USFWS) WNS Decontamination Guidelines [40]. All 


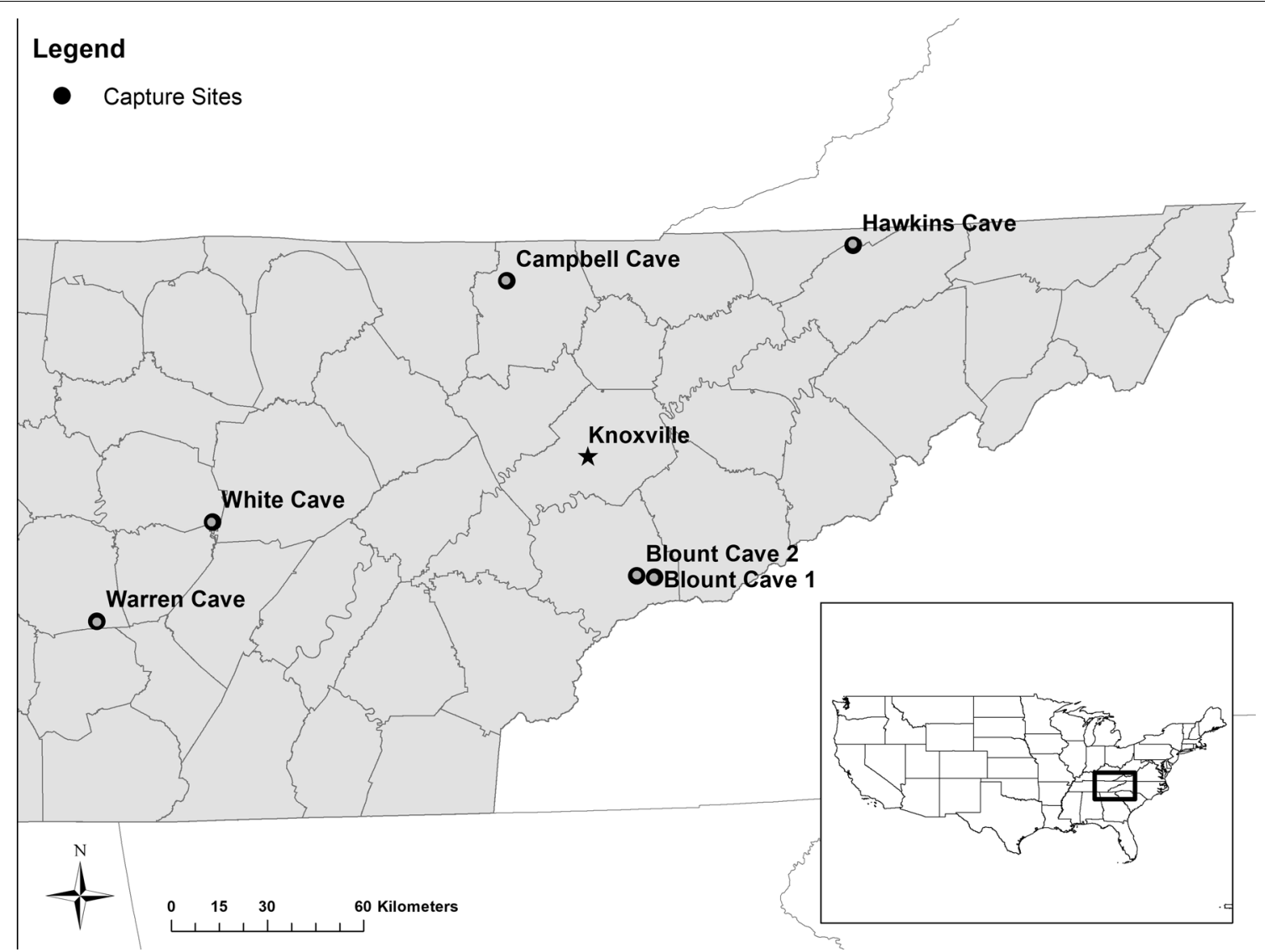

Fig. 1 Bat capture sites at cave hibernacula in middle and east Tennessee, U.S. Bats were captured during hibernation (October-April) 2012/20132017/2018 at six cave sites using mist-nets deployed at least once per month for five hours starting 30 min before civil sunset

capture and handling techniques were approved by the University of Tennessee Institute of Animal Care and Use Committee (IACUC 2026-0514 and IACUC 2253-0320) and were consistent with the guidelines put forth by the American Society of Mammalogists (Sikes and ACUC 2016). We obtained federal (USFWS TE-71613A and USFWS TE-35313B, GRSM-2013-SCI1053; GRSM-2014SCI1053, GRSM-2016-SCI1253， GRSM-2018-SCI1253) and state (TWRA 3716, TWRA 3741, TDEC 2009-038, TDEC 2011-031) permits to capture and handle bats and collect samples at winter hibernacula.

\section{Dietary analysis}

The winter collection period was divided into three periods, which corresponded to the depth of winter (documented by mean nightly temperature) in Tennessee: early-hibernation $=$ October $\quad-$ November $\left(14.01{ }^{\circ} \mathrm{C} \pm 1.11 \mathrm{SE}\right)$; mid-hibernation $=$ December-February $\left(7.30{ }^{\circ} \mathrm{C} \pm 1.05 \mathrm{SE}\right)$; and late-hibernation $=$ March April (14.52 $\left.{ }^{\circ} \mathrm{C} \pm 1.09 \mathrm{SE}\right)$. Fecal samples used in this analysis were selected based on size of sample (2-4 pellets, up to $50 \mathrm{mg}$ ), species, sex, site, and winter collection period. We extracted DNA from feces using PowerSoil ${ }^{\circledR}$ (MO BIO Laboratories, Inc., Carlsbad, CA, U.S.) or QIAamp PowerFecal (Qiagen, Germantown, MD, U.S.) DNA Isolation Kits following the manufacturers' protocols with one minor modification of increasing the first incubation period at $4{ }^{\circ} \mathrm{C}$ from $30 \mathrm{~min}$ to $12 \mathrm{~h}$, to enhance removal of pigment from the DNA extraction product. We included one reagent-only control in each set of reactions (i.e., one control for every 24 samples) and stored extracted DNA at $-20{ }^{\circ} \mathrm{C}$ prior to Polymerase Chain Reaction (PCR) amplification. We targeted the mitochondrial cytochrome c oxidase 1 (CO1) gene using insect primers developed by Zeale et al. [41] (ZBJ-ArtF1c and ZBJ-ArtR2c). Conditions for PCR amplification and library prep were similar to those listed in Divoll et al. [42]. We amplified samples collected during the winters of 2012/2013 and 2013/2014 with primers modified for the Ion Torrent platform (Life Technologies, Carlsbad, CA, U.S.) with adapters and unique 10-base indexes, and samples collected during the winters of $2015 / 2016$, $2016 / 2017$, and $2017 / 2018$ with primers containing 
adapters modified for the MiSeq platform (Illumina, San Diego, CA, U.S.).

During library preparation, we purified Ion Torrent samples with Agencourt AMPure XP beads (Beckman Coulter, Brea, CA, U.S.), prepared with an Ion Plus Fragment Library Kit (Life Technologies, Carlsbad, CA, U.S.), then size-selected for products of approximately 300 bp on the Pippin Prep (Sage Science, Beverly, MA, U.S.) before re-purifying with AMPure beads. We confirmed the quality and quantity of final products on a Bioanalzyer (Agilent Technologies, Santa Clara, CA, U.S.), pooled at approximately equimolar concentrations, loaded on an Ion 318 chip to run on the ION Torrent at the University of Tennessee Genomics Core. Library preparation for the Illumina MiSeq samples involved purifying the PCR products with Agencourt AMPure XP beads, dual-indexing with Illumina Nextera XT indexes, and re-purifying with Agencourt AMPure XP beads. We confirmed the quantity and quality of final products on a Bioanalzyer, pooled at approximately equimolar concentrations, and loaded at $6 \mathrm{pM}$ with $20 \%$ PhiX on a v2, 500 cycle flow-cell reading 225 bases, paired-end, on the Illumina MiSeq at the University of Tennessee Genomics Core.

We analyzed sequences using the QIIME platform [43] and the workflows outlined in Divoll et al. [42] and Cravens et al. [44], with an additional step to eliminate potentially chimeric sequences. Briefly, we demultiplexed samples and pooled sequences in the forward and reverse direction into one fasta file with the same orientation. We then clipped primer sequences and removed any sequence that did not contain both forward and reverse primer sequences from further analysis. We clustered sequences into operational taxonomic units (OTUs) using the SWARM method with a resolution of two. We extracted representative sequences from each OTU cluster to create an OTU table based on abundance and used the 'usearch' command with denovo filtering in QIIME 2 to remove potentially chimeric sequences from the clustered OTUs. We removed sequences shorter than $147 \mathrm{bp}$ or longer than $167 \mathrm{bp}$, representing ten bases on each side of the expected 157 bp. Due to potential index jumping, we conservatively removed any sequence that appeared in an individual bat less than 10 times for Ion Torrent data and less than 50 times for MiSeq data.

We ran the representative set of sequences through the COI database in the Barcode of Life Database (BOLD; [45]) using the package "bold" [46] in R [47]. We considered the first 40 records for each representative OTU and removed records with $\leq 99 \%$ similarity and country of collection outside of the U.S. and Canada [42, 44]. Where more than one identification for an OTU was present at $\geq 99 \%$, we deferred to the next highest level of taxonomy for identification (i.e., multiple species within an order, we deferred to the order). We collapsed unique OTUs assigned to the same taxonomy into a single OTU, representing one bat prey item. We also merged duplicate OTUs, identified via the same unique BOLD identification number or within 1-4 bp via Sequencher (Gene Codes Corporation, Ann Arbor, MI, U.S.). We ran sequences produced from both the IonTorrent and MiSeq through the BOLD identification pipeline together to ensure consistent taxonomic identifications.

\section{Statistical analysis}

We calculated the relative read abundance (RRA) of OTUs (i.e., the proportion of reads per each prey item in each sample) for each bat species following descriptions by Deagle et al. [48] and Vesterinen et al. [49]. We assessed sample coverage using the iNEXT package [50] to determine accuracy in describing the diversity of arthropod prey in the bat diet with respect to our sampling effort [51-53]. We plotted extrapolation curves using the entire sample set with all OTUs, including those that were not identified to any taxonomic level in BOLD, and used species richness (Hill number; $q=0$ ) as the diversity measure [50,52]. We used the VEGAN package [54] to test for variation in prey composition among bat species and hibernation periods using ANOSIM (Analysis of Similarity; [55] and PERMANOVA (Permutational Multivariate Analysis of Variance, adonis function) tests with 999 permutations. We grouped prey by family or order to minimize zero-inflated counts. To visually inspect the variation in prey consumption by arthropod species, family, and order consumed across bat species and hibernation periods, we used the ordination technique of nonmetric multidimensional scaling (NMDS) in VEGAN. We used a Bray-Curtis dissimilarity distance measure to calculate distances among samples and assessed the fit of the NMDS by observing the "stress" value [54]. Finally, we used the bipartite package [56] to draw an interaction web for each bat species using RRA. All statistical analyses and visualizations were performed using R [47].

\section{Results \\ Bat captures}

We captured 2044 individuals of 10 bat species over five winters. None of the 13 Lasionycteris noctivagans (silver-haired bat) captured provided fecal samples, therefore our analysis includes feces from nine species. We collected 518 fecal samples, on 84 of the 154 successful capture nights, with $25 \%$ of bats captured providing feces (Table 1). The mean nightly temperature on nights that samples were provided was $9.85{ }^{\circ} \mathrm{C} \pm 0.87 \mathrm{SE}$, with temperatures ranging from -2.03 to $20.16{ }^{\circ} \mathrm{C}$. Of the fecal 
Table 1 Total number of bats captured in Tennessee during hibernation (October-April) 2012/2013 to 2017/2018

\begin{tabular}{lllll}
\hline Species $^{\text {a }}$ & Total bats captured & Total fecal samples & $\begin{array}{c}\text { \% Fecal provided } \\
\text { b }\end{array}$ & $\begin{array}{l}\text { Samples } \\
\text { analyzed }^{\text {c }}\end{array}$ \\
\hline Corynorhinus rafinesquii (CORA) & 21 & 10 & 47.6 & 7 \\
Eptesicus fuscus (EPFU) & 121 & 18 & 14.9 & 11 \\
Lasiurus borealis (LABO) & 15 & 5 & 33.3 & 5 \\
Lasionycteris noctivagans (LANO) & 13 & 0 & 0 & - \\
Myotis grisescens (MYGR) & 754 & 156 & 20.7 & 65 \\
Myotis leibii (MYLE) & 288 & 130 & 45.1 & 85 \\
Myotis lucifugus (MYLU) & 54 & 17 & 31.5 & 9 \\
Myotis septentrionalis (MYSE) & 224 & 55 & 24.6 & 26 \\
Myotis sodalis (MYSO) & 350 & 110 & 31.4 & 65 \\
Perimyotis subflavus (PESU) & 204 & 17 & 8.3 & 10 \\
Grand total & 2044 & 518 & 25.3 & 283 \\
\hline
\end{tabular}

Each row represents the total number of individuals captured per species, including the total number of fecal samples collected and analyzed

${ }^{\text {a }}$ CORA = Rafinesque's big-eared bat, EPFU = big brown bat, LABO = red bat, LANO = silver-haired bat, MYGR=gray bat; $M Y L E=$ eastern small-footed bat, MYLU = little brown bat, $\mathrm{MYSE}=$ northern long-eared bat, $\mathrm{MYSO}=$ Indiana bat, $\mathrm{PESU}=$ tri-colored bat

b \% Fecal provided: percent of individuals that provided a fecal sample

' Samples analyzed: total number of fecal pellets amplified and sequenced

pellets collected, we selected 284 fecal pellet samples (117 samples from 2012/2013 and 2013/2014, and 168 samples from 2015/2016, 2016/2017 and 2017/2018) that met our criteria for analysis (i.e., early-hibernation: $\mathrm{n}=136$, midhibernation: $\mathrm{n}=38$, late-hibernation: $\mathrm{n}=110$ ).

\section{Dietary analysis}

After bioinformatics processing and clean-up, we clustered and filtered sequencing reads to a total of 1209 unique OTUs. Of the unique OTUs, we identified 716 $(59.2 \%)$ with matching sequences in BOLD, belonging to 14 orders, 134 families, and 587 genera or species (Additional file 2: Table S1). We were unable to identify the remaining 493 OTUs, likely due to a lack of reference sequences in BOLD and GenBank (Additional file 3: Table S2). Sample coverage of dietary diversity for all bat species amounted to 0.7832 ( $\pm 0.011 \mathrm{SE}$; Fig. 2a) and species diversity (Hill number $\mathrm{q}=0$ ) accumulation curve of arthropods detected in the diet in relation to the number of fecal samples was near its asymptotic point. Sample coverage for individual bat species varied (Fig. 2b). Of the unique OTUs, 762 were represented in (i.e., consumed by) one bat each, with the remaining 447 OTUs represented in two to 62 bats (Additional file 4: Table S3). The number of OTUs per bat fecal sample ranged from one to 58 with a mean of $10.44 \pm 0.495$ SE OTUs per fecal sample.

The dispersion of diets varied weakly among bat species (PERMANOVA: $\mathrm{R}^{2}=0.046, P=0.001$ ); however, diet composition was not significantly different (ANOSIM: $\mathrm{R}=0.058, P=0.400$; Fig. 3). Diptera, Hemiptera, and Lepidoptera were consumed by every species of bat for which fecal samples were collected $(n=9)$. Over half of the samples of Corynorhinus rafinesquii (Rafinesque's big-eared bat; 72.2\%) and Lasiurus borealis (red bat; 67.4\%) contained Lepidoptera. Diptera were the most common order of prey present in the diet of $M$. leibii (eastern small-footed bat; 32.4\%), M. lucifugus (little brown bat; 37.4\%), M. sodalis (Indiana bat; 35.5\%) and Perimyotis subflavus (tri-colored bat; 68.8\%). Coleoptera and Neuroptera were consumed by eight bat species; Ephemeroptera, Psocodea, Psocoptera and Trichoptera by seven bat species; Araneae and Hymenoptera by six bat species; Plecoptera and Trombidiformes by four bat species; and Orthoptera by three bat species (Table 2). Every species of bat consumed at least one OTU that was unidentified, comprising $7-33.4 \%$ of all reads.

Myotis species had the most diverse diets among the five genera of bats examined, ranging from 11 to 14 orders (Fig. 4). Excluding unidentifiable OTUs, C. rafinesquii had the least diverse diet ( $\mathrm{n}=6$ orders), followed by $L$. borealis and P. subflavus ( $\mathrm{n}=8$ orders), and E. fuscus $(\mathrm{n}=11$ orders). Eptesicus fuscus consumed the highest proportion of unidentifiable OTUs (33.4\%).

The two Diptera species (Dicranomyia; Limoniidae) and an unknown Diptera were the most consumed OTUs detected in samples (Table 2). Four lepidopteran species were among the top 10 most common OTUs detected in samples, specifically, Machimia tentoriferella (Depressariidae), Chionodes thoraceochrella (Gelechiidae), Sinoe chambersi (Gelechiidae), and Sitotroga cerealella (Gelechiidae). Four additional OTUs, which were not identified to Order, were also represented in the top 10 prey OTUs detected. 

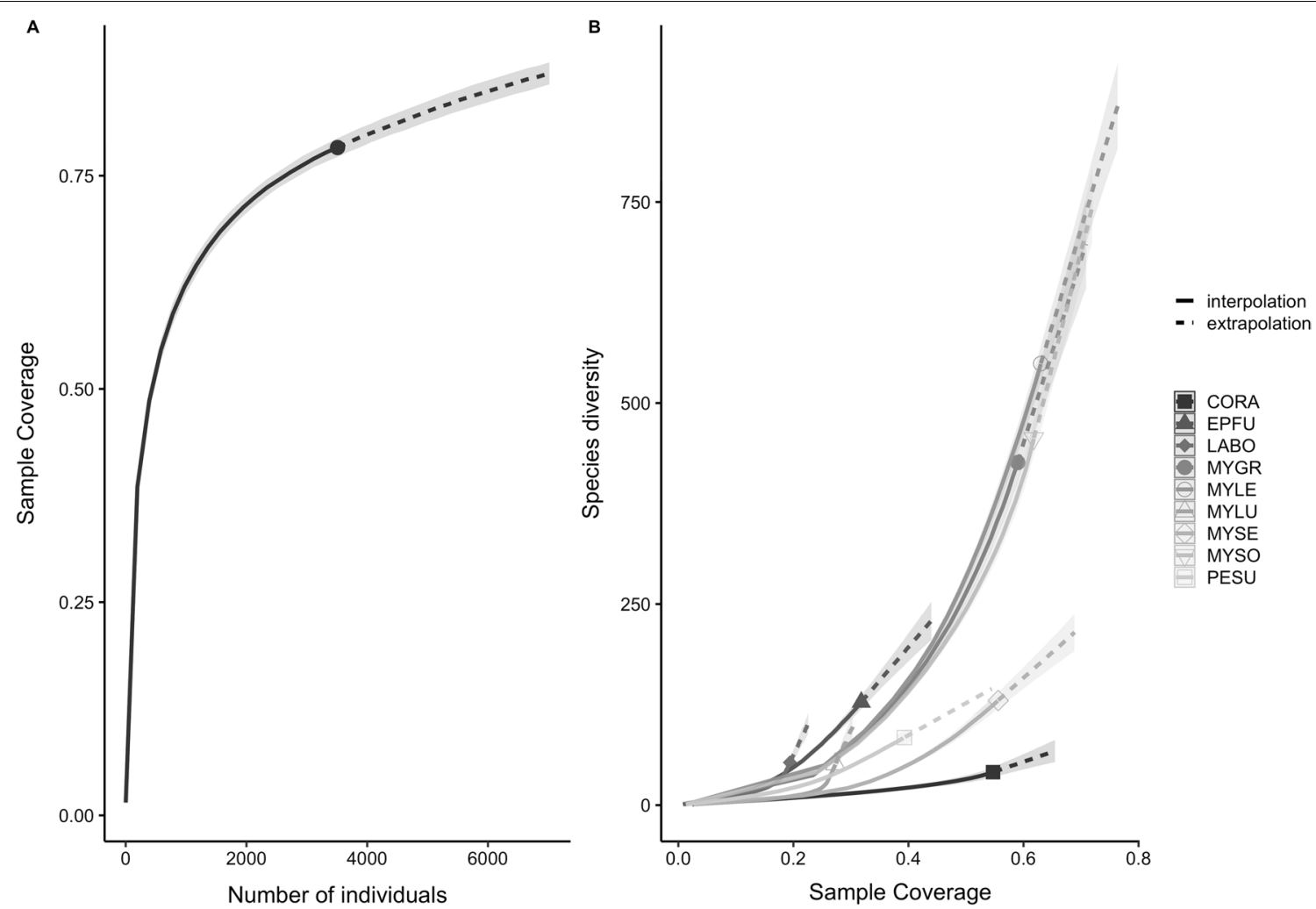

Fig. 2 a Sample coverage for arthropod prey detected in all nine bat species captured throughout hibernation (October-April) 2012/20132017/2018 at cave sites in middle and east Tennessee, U.S. b Sample coverage by species diversity for each of the nine bat species captured. Interpolation (solid line segments) and extrapolation (dashed line segments) estimates of sample coverage were calculated as a function of sampling units produced in package iNEXT. We used Hill number $q=0$ to calculate curves for species richness. $95 \%$ confidence intervals for each estimate are represented in shaded areas. Species acronyms: CORA: Corynorhinus rafinesquii (Rafinesque's big-eared bat), EPFU: Eptesicus fuscus (big brown bat), LABO: Lasiurus borealis (red bat), MYGR: Myotis griscesens (gray bat), MYLE: Myotis lebii (eastern small-footed bat), MYLU: Myotis lucifugus (little brown bat), MYSE: Myotis septentrionalis (northern long-eared bat), MYSO: Myotis sodalis (Indiana bat), and PESU: Perimyotis subflavus (tri-colored bat)

Eight of the top 10 prey species detected in the diet of $C$. rafinesquii were lepidopterans with four representing the Family Noctuidae (Table 2). The most common OTUs for E. fuscus were all lepidopteran species, including Argyrotaenia velutiana (Tortricidae). At least 2 individuals from each species of Myotis consumed the lepidopteran, Chionodes thoraceochrella (Gelechiidae). The commonly detected OTU for P. subflavus was an unidentified OTU (Table 2).

The dispersion of diets varied among hibernation periods (PERMANOVA: $\mathrm{R}^{2}=0.01246, P=0.001$ ); however, diet composition was not significantly different (ANOSIM: $\mathrm{R}=0.049, P=0.7$; Fig. 5). All 14 orders were consumed throughout early- and late-hibernation. Twelve orders were consumed during mid-hibernation (December - February), where the most dominant orders were Diptera (28.3\% of all reads) and Lepidoptera (21.5\% of all reads). Dipteran and lepidopteran species were consistently the most common food source throughout hibernation, ranging from $26.1 \%$ (late hibernation) to $34.1 \%$ (early hibernation) for Diptera, and 28.3\% (early hibernation) to $36.7 \%$ (late hibernation) for Lepidoptera. The largest proportion of unidentified sequenced reads were from mid-hibernation (31.6\%). All orders except Orthoptera and Trombidiformes were consumed throughout winter.

\section{Discussion}

We found that bats actively forage and consume a wide diversity of prey during winter. Augmenting energy stores may be particularly critical for hibernating bats due to the ability to supplement energy stores lost during hibernation. This may be even more important due to the additional energetic burden of $P d$ infection and manifestation of WNS. The similarity in the dietary breadth of insects consumed per species suggests that bats are not preferentially selecting large, calorie-rich prey $[57,58]$. 


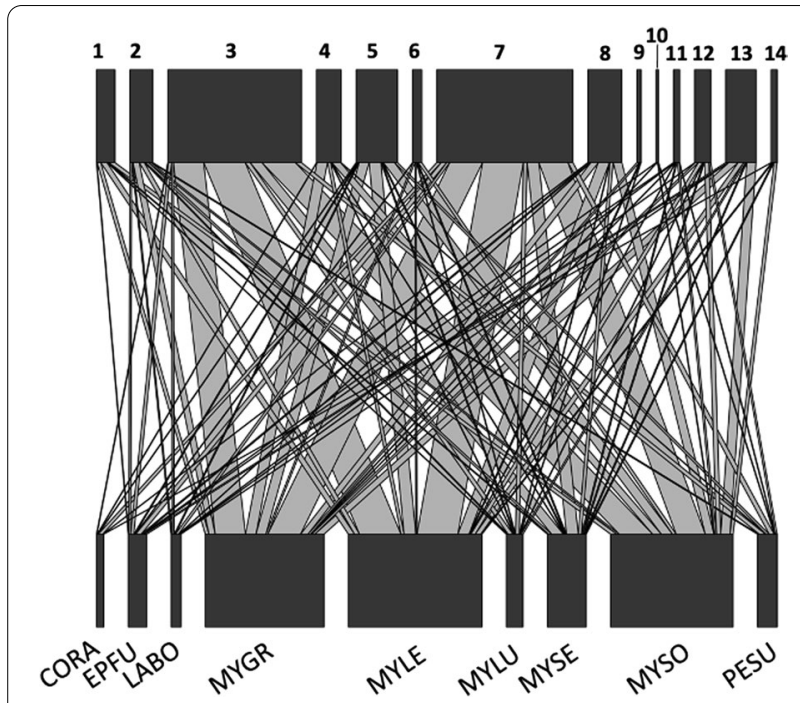

Fig. 3 Food web of bat species and their arthropod prey species visualizing the similarities in the diet. The upper row represents arthropod orders consumed, with the blocks in the lower row the bat species. Lines connecting a bat species with an arthropod order represents the identification of consumption, and the thickness of the line represents the total number of times the order was represented in each bat species. Numbers correspond to 1: Araneae, 2: Coleoptera, 3: Diptera, 4: Ephemeroptera, 5: Hemiptera, 6: Hymenoptera, 7: Lepidoptera, 8: Neuroptera, 9: Orthoptera, 10: Plecoptera, 11: Psocodea, 12: Psocoptera, 13: Trichoptera, and 14: Trobidiformes. Unidentified OTUs were not included in this figure

While opportunities for foraging during winter are likely a limiting factor when compared to insect abundance in summer, we found that the RRA of the two most common orders, Diptera and Lepidoptera, remained consistent across our sampling period (early to late hibernation). We also note that the presence of 14 insect orders and over 700 insect OTUs in the winter diet of bats is equivalent, if not greater, than what has been documented in molecular studies conducted in summer [3436]. This provides another line of evidence that bats may be eating whatever is available to them during winter.

Although the dietary composition across bat species was not statistically different, the species-specific 'preference' of prey based on their respective ecologies were consistent with diet studies conducted in summer (see 34-36). Corynorhinus rafinesquii consumed the narrowest range of prey, seeming to focus primarily on lepidopteran species. This species of bat is a known moth specialist, gleaning individuals off of the surface of vegetation and other substrates, and has been found to predominately consume species in the families Noctuidae and Geometridae [59-63]. Although Noctuidae species comprised nearly half of the lepidopteran species detected in winter $(n=8 / 18$ species represented), we also detected multiple species from the families
Depressariidae, Erebidae, Geometridae and Tortricidae in samples from C. rafinesquii. We found three prey Orders, including Ephemeroptera, Hemiptera, and Trombidiformes, which, to our knowledge, have not been documented in previous dietary studies of the species (Additional file 4: Table S3). All representative species were consumed during early or mid-hibernation.

The remaining eight bat species we sampled are considered predominately generalist insect consumers [64], and we found that Myotis species consumed the most diverse prey items. A large proportion of the OTUs detected in samples from M. grisescens and M. sodalis were comprised of aquatic species, including Diptera, Ephemeroptera, Hemiptera, Neuroptera, Plecoptera and Trichoptera, including 168 and 167 representatives in the diet of the two species, respectively. While our study was conducted during winter, these findings are consistent with the foraging ecology of the two bat species [65, 66]. Visual identification of $M$. sodalis guano collected during the summer suggests the species frequently consumes Diptera, Coleoptera, Lepidoptera and Trichoptera [67-70]. Research on the summer diet of $M$. grisescens indicates that the species forages low over streams and other bodies of water [71]. As these streams do not typically freeze during winter in Tennessee, the preferred prey of $M$. grisescens, aquatic-based insects, appear to be available year-round in the Southeast [71]. Thus, the year-round availability of aquatic-based insects in the Southeast appears to enable the species to maintain opportunistic selection of their preferred prey base throughout hibernation [71].

Interestingly, Araneae species were most commonly consumed by Myotis species, ranging from an individual record in M. lucifugus (Philodromus rufus vibrans) to 16 Araneae species in M. sodalis. Anyphaena pectorosa, a species of ghost spider, was consumed by five $M$. sodalis during early hibernation. Interestingly, this species is typically active above-ground for a short period of time between mid-June to mid-July [72] and can often be seen in low foliage or under rocks [73]. Thus, the consumption of this and other Araneae species most likely occurs opportunistically while bats are roosting in hibernacula [74].

Eptesicus fuscus, the largest of the nine species captured, was once considered a coleopteran specialist $[75$, 76]. However, recent studies [35], including our own, place them more as generalist consumers throughout the year. Only five coleopteran species were consumed by $E$. fuscus, substantially less than the number of representatives consumed by M. grisescens, M. leibii, M. septentrionalis, and $M$. sodalis. The lack of coleopteran species in the diet of E. fuscus could be attributed to seasonal variation and availability [35]. Alternatively, the seemingly 


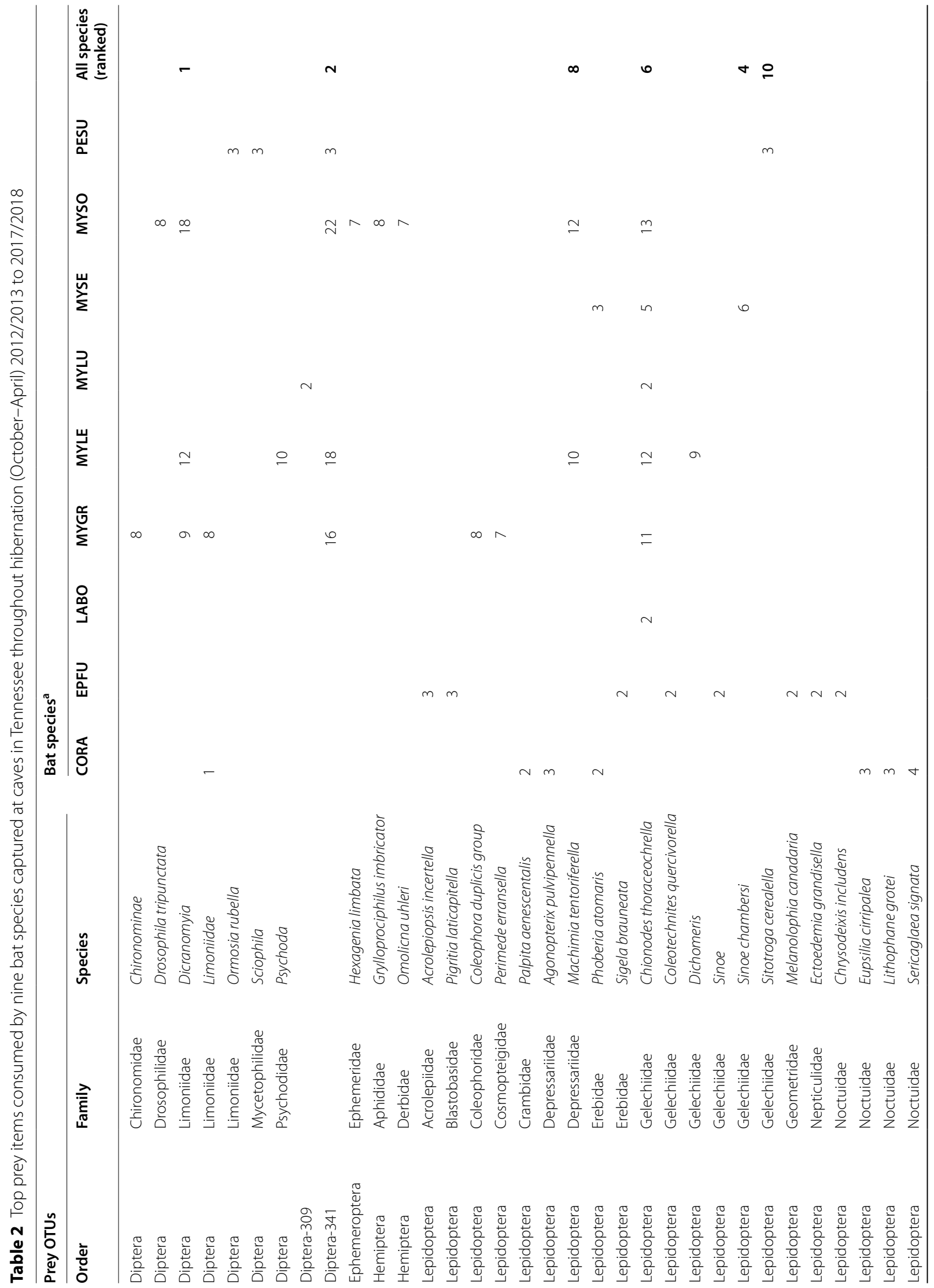




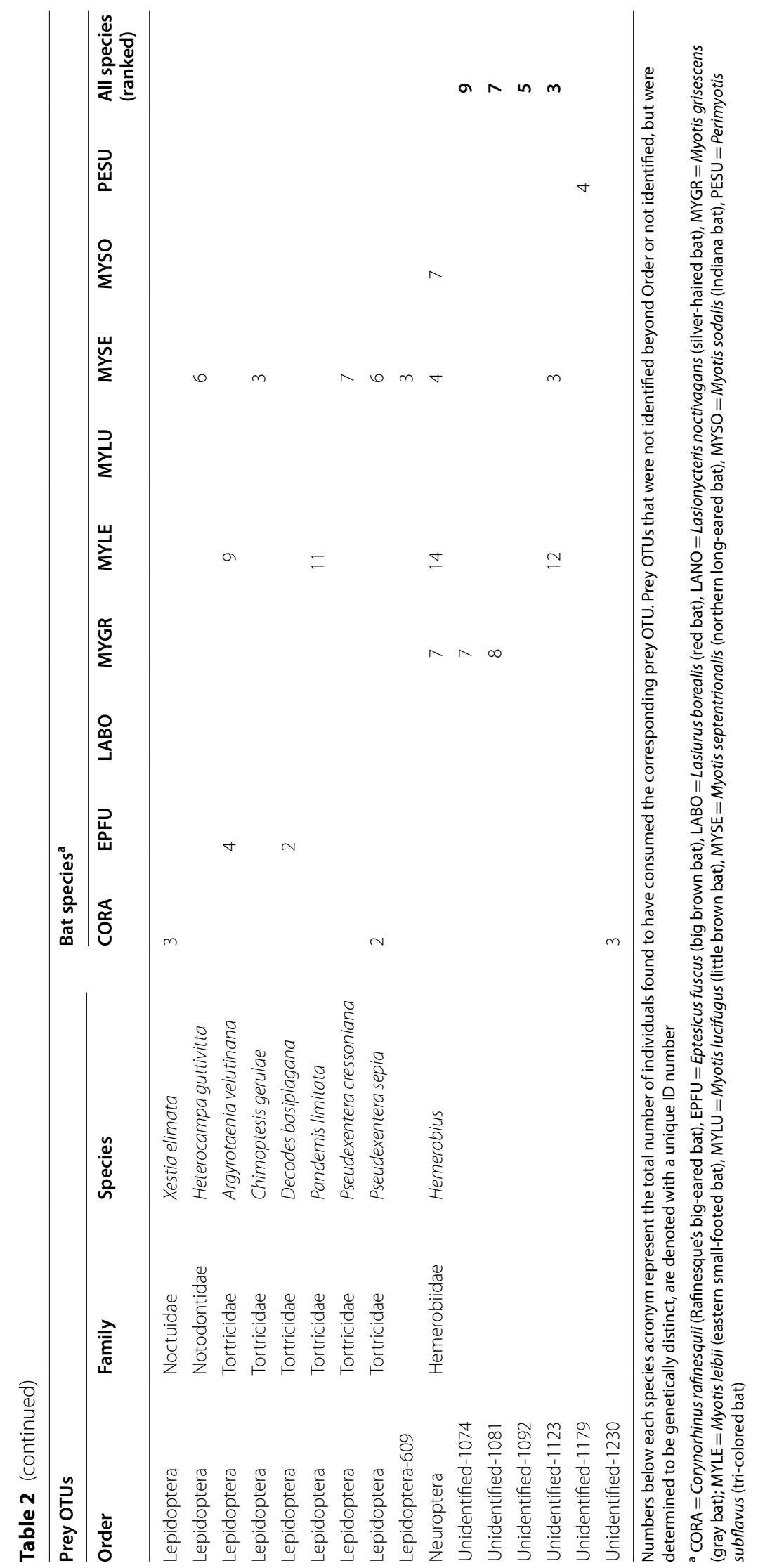




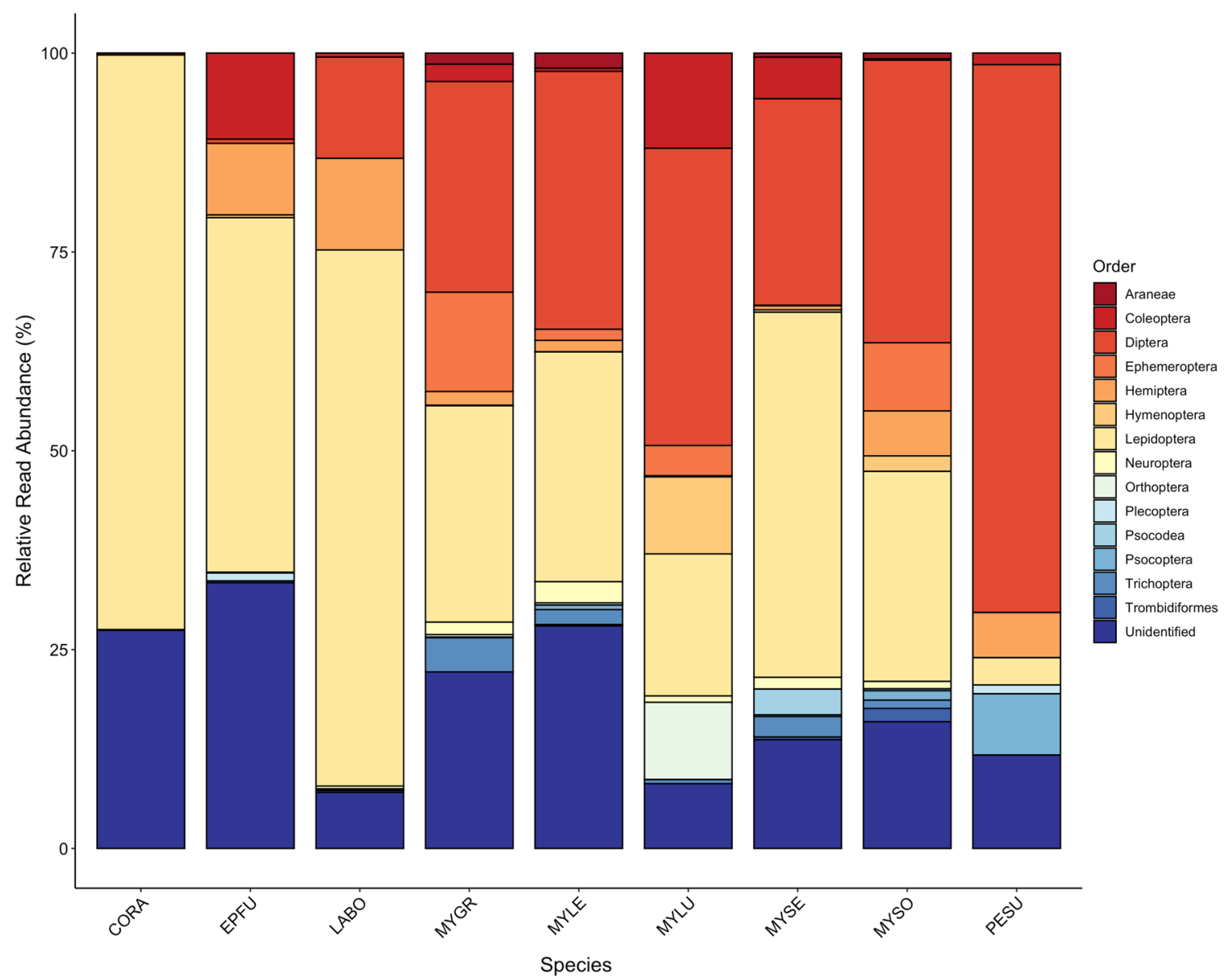

Fig. 4 Relative read abundance (RRA) of arthropod Orders consumed by nine species of bat captured outside of caves in Tennessee during hibernation (October-April) 2012/2013 to 2017/2018. OTUs were identified to the finest taxonomic resolution possible using BOLD and GenBank. Those that were not identified are listed as "unidentified". All years and seasons are combined. Species acronyms: CORA: Corynorhinus rafinesquii (Rafinesque's big eared bat), EPFU: Eptesicus fuscus (big brown bat), LABO: Lasiurus borealis (red bat), MYGR: Myotis griscesens (gray bat), MYLE: Myotis lebii (eastern small-footed bat), MYLU: Myotis lucifugus (little brown bat), MYSE: Myotis septentrionalis (northern long-eared bat), MYSO: Myotis sodalist (Indiana bat), and PESU: Perimyotis subflavus (tri-colored bat)

low proportion of Coleoptera in the diet, especially when compared to the proportion of unidentified OTUs consumed by E. fuscus, could be due to the specific primers we used or a lack of genetic information in BOLD for Coleopteran species active in winter.

The winter consumption of insects by bats has illuminated the need for further research on the year-round foraging behavior of this diverse taxonomic group, as well as the activity and abundance of insects active throughout winter. Although over $50 \%$ of the identified reads were dipteran and lepidopteran species, information on the specific behaviors of these insect orders during winter is lacking. We collected a substantial number of samples for both early and late hibernation (136 and 109 bats, respectively), indicating that favorable weather conditions and presumably increased prey availability allow for successful foraging. Although there is evidence that some lepidopteran species in temperate regions remain active as caterpillars [77-79], it is unclear how many species of adult lepidoptera remain active in winter. Both morphological and molecular dietary studies have identified adult Lepidoptera in the diet of bats during winter, with many of those studies conducted in climates with more severe winters than in the southeastern portion of the U.S. [13, 22, 80-82]. Ultimately, there remains a significant knowledge gap about the winter activity of insects in the southeastern U.S.

As we consider the conservation implications of periodic activity and foraging throughout winter, we must also be cognizant of the plasticity in torpor of temperate North American bats [5, 83]. Prior to the emergence of WNS in North America, the predominant theory was that most bat species entered hibernation in October and remained in hibernacula until March-April [31]. We 


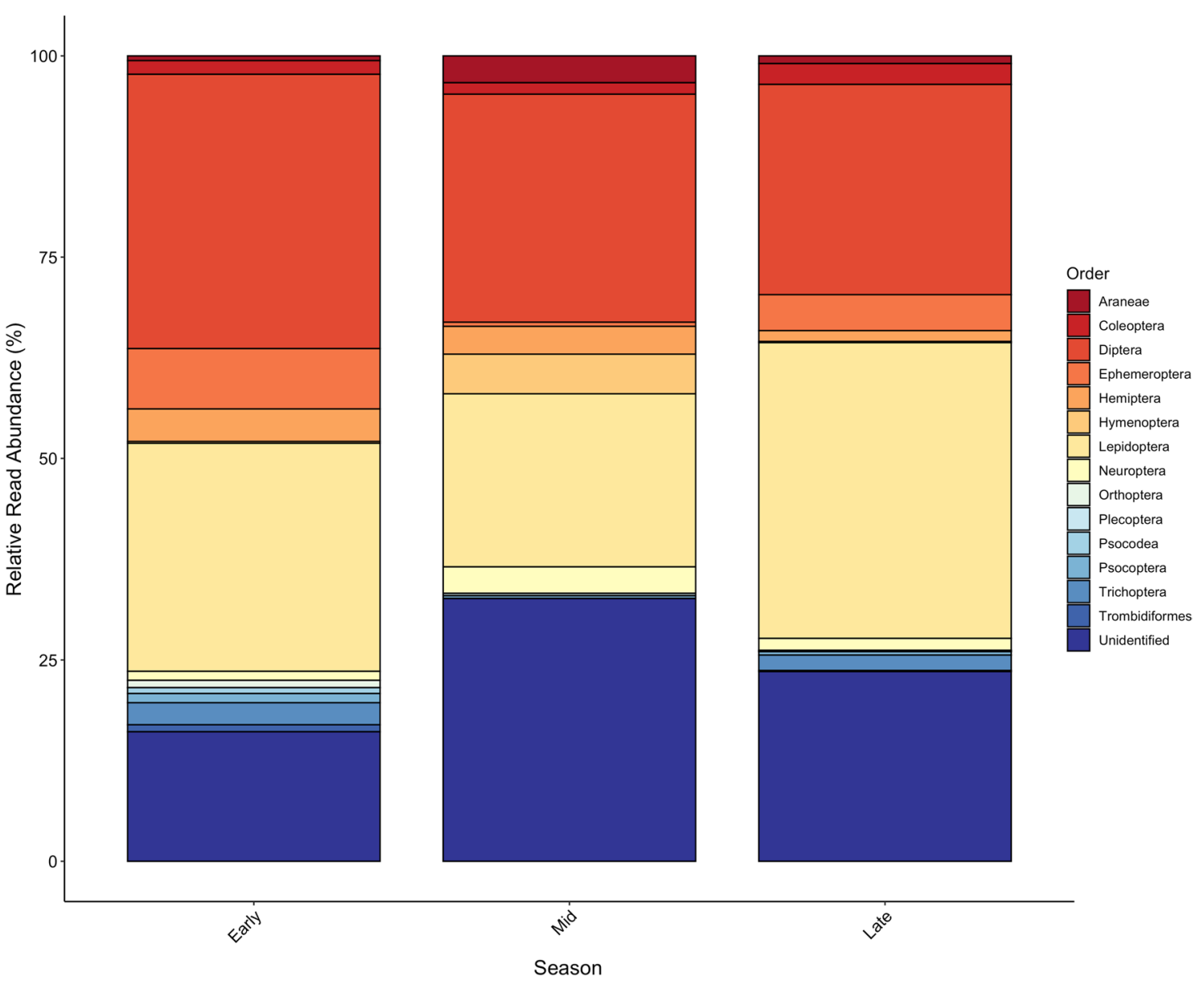

Fig. 5 Relative read abundance (RRA) of arthropod Orders consumed by bats throughout three hibernation periods: early (October-November), mid (December-February) and late (March-April) of 2012/2013 to 2017/2018. OTUs were identified to the finest taxonomic resolution possible using BOLD and GenBank. Those that were not identified are listed as "unidentified". All years and bat species are combined

provide evidence that several bat species in the Southeast forage for aerial insects during winter. This knowledge is critical for natural resource managers, as it may allow for novel conservation actions that could enhance survival of overwintering bats (e.g., insect habitat management or artificial lights near hibernacula to attract insect prey). By enhancing insect habitat and abundance near bat hibernacula, the energetic costs of foraging could be minimized, thereby increasing fat storage and survival, particularly amongst WNS-susceptible species. As we confront a rapidly warming climate, we expect winter activity of bats will increase in more northern latitudes $[84,85]$. Therefore, increasing knowledge of the winter activity of bats will have importance even after WNS is deemed endemic in North America.

\section{Supplementary Information}

The online version contains supplementary material available at https://doi. org/10.1186/s12983-021-00434-9.

\section{Additional file 1}

Additional file 2: Table S1. Of the unique OTUs represented in the diet of bats, we identified 587 OTUS to genera or species. Rows labeled in bold with a sample size represent OTUs that were only identified to Order. We were unable to identify 493 OTUs. Total sequence reads represents the number of times the OTU sequence was represented and can be used as a relative abundance with larger number indicating more DNA was represented. Represented signifies the number of bats found to have consumed each OTU.

Additional file 3: Table S2. FASTA file with all sequence reads, prior to the removal of duplicate or redundant IDs. This fasta file is the merged sequence file from the lon Torrent and MiSeq samples.

Additional file 4: Table S3. This table highlights the relative read abundance of all OTUs consumed across all bat samples. Each bat sample is an individual identified by hibernation period (hiber), species and sex.

\section{Acknowledgements}

We thank our field and lab assistants: Charlie Cianciolo, Anna Chow, Keith Dreyer, D. Scott Hollis, Devin Jones, Mariah Patton, Ana Reboredo-Segovia, Mallory Tate and Laura Vining. We are also very appreciative of our funding agencies: Tennessee Wildlife Resources Agency, Great Smoky Mountains National Park, Basically Bats Wildlife Conservation Society, Inc., Great Smoky Mountains Conservation Association, and the University of Tennessee Institute 
of Agriculture Center for Wildlife Health. We also thank Great Smoky Mountains National Park, Tennessee Wildlife Resources Agency, and the Tennessee Chapter of the Nature Conservancy for allowing us to study bats and insects flying and foraging within their management jurisdictions. Finally, thanks to Dr. Thomas Lilley and Devin Jones for providing comments on early versions of the manuscript.

\section{Authors' contributions}

RFB originally formulated the idea and study design. RFB, EVW, and RTJ conducted field work. RFB, RTJ, and VAB conducted lab work. VAB generated sequencing data. RFB analyzed the data. RFB, EVW, and GFM attained funding. RFB, EVW, RTJ, and VAB wrote the manuscript. GFM provided advice on project design and manuscript. All authors read and approved the final manuscript.

\section{Availability of data and material}

All data are available as supplemental files.

\section{Declarations}

\section{Ethics approval and consent to participate}

All applicable institutional and/or national guidelines for the care and use of animals were followed.

\section{Consent for publication}

The authors declare that they have agreed to publish this manuscript in its current form.

\section{Conflict of interests}

The authors declare that they have no conflict of interest.

\section{Author details}

'Department of Zoology and Physiology, University of Wyoming, Laramie 82071, USA. ${ }^{2}$ Department of Forestry, Wildlife and Fisheries, University of Tennessee, Knoxville 37996, USA. ${ }^{3}$ Department of Ecology and Evolutionary Biology, University of Tennessee, Knoxville 37996, USA. ${ }^{4}$ Department of Biological Sciences, University of Arkansas, Fayetteville 72701, USA. ${ }^{5}$ Center for Environmental Biotechnology, University of Tennessee, Knoxville 37996, USA.

Received: 10 August 2021 Accepted: 9 September 2021 Published online: 23 September 2021

\section{References}

1. Geiser F. Metabolic rate and body temperature reduction during hibernation and daily torpor. Annu Rev Physiol. 2004;66:239-74.

2. Boyles JG, Johnson JS, Blomberg AS, Lilley TM. Optimal hibernation theory. Mamm Rev. 2020;50:91-100.

3. Aschoff J. Thermal conductance in mammals and birds: Its dependence on body size and crcadian phase. Comp Biochem Physiol Part A Physiol. 1981;69:611-9.

4. Taylor LR. Analysis of the effect of temperature on insects in flight. J Anim Ecol. 1963;32:99-117.

5. Dunbar MB, Tomasi TE. Arousal patterns, metabolic rate, and an energy budget of eastern red bats (Lasiurus borealis) in winter. J Mamm. 2006;87:1096-102.

6. Stawski C, Turbill C, Geiser F. Hibernation by a free-ranging subtropical bat (Nyctophilus bifax). J Comp Physiol B Biochem Syst Environ Physiol. 2009;179:433-41.

7. Boyles JG, Dunbar MB, Whitaker JO Jr. Activity following arousal in winter in North American vespertilionid bats. Mamm Rev. 2006;36:267-80.

8. Boyles JG, Swart JM, Bennett NC, Ferguson W, Speakman JR, Scantlebury DM. Energetics suggest cause for even further conservation concern for Temminck's ground pangolin. Anim Conserv. 2019;23:245-9.

9. Ruf T, Geiser F. Daily torpor and hibernation in birds and mammals. Biol Rev. 2015;90:891-926.

10. Turbill C, Geiser F. Hibernation by tree-roosting bats. J Comp Physiol B Biochem Syst Environ Physiol. 2008;178:597-605.
11. McNab BK. Short-term energy conservation in endotherms in relation to body mass, habits, and environment. J Therm Biol. 2002;27:459-66.

12. Speakman JR, Rowland A. Preparing for inactivity: how insectivorous bats deposit a fat store for hibernation. Proc Nutr Soc. 1999;58:123-31.

13. Dunbar MB, Whitaker JO Jr, Robbins LW. Winter feeding by bats in Missouri. Acta Chiropterologica. 2007;9:305-22.

14. Thomas DW. Hibernating bats are sensitive to nontactile human disturbance. J Mamm. 1995;76:940-6.

15. Jonasson KA, Willis CKR. Hibernation energetics of free-ranging little brown bats. J Exp Biol. 2012;215:2141-9.

16. Czenze ZJ, Park AD, Willis CKR. Staying cold through dinner: cold-climate bats rewarm with conspecifics but not sunset during hibernation. J Comp Physiol B. 2013;183:859-66.

17. Viele DP, Kurta A, Kath JA. Timing of nightly emergence. Indiana Bat Biol Manag an endagered species. 2002;199-207.

18. Mumford RE. Natural history of red bat (Lasiurus borealis) in Indiana. Period Biol. 1973;75:155-8.

19. Whitaker JO Jr, Rissler LJ. Do bats feed in winter? Am Midl Nat. 1993;129:200-3.

20. Whitaker JO Jr, Rose RK, Padgett TM. Food of the red bat Lasiurus borealis in winter in the Great Dismal Swamp, North Carolina and Virginia. Am Midl Nat. 1997;137:408-11.

21. Hope PR, Jones G. Warming up for dinner: torpor and arousal in hibernating Natterer's bats (Myotis nattereri) studied by radio telemetry. J Comp Physiol B. 2012;182:569-78.

22. Hope PR, Bohmann K, Gilbert MTP, Zepeda-Mendoza M, Razgour O, Jones $\mathrm{G}$. Second generation sequencing and morphological faecal analysis reveal unexpected foraging behaviour by Myotis nattereri (Chiroptera, Vespertilionidae) in winter. Front Zool. 2014;11:39.

23. Avery MI. Winter activity of Pipistrelle bats. J Anim Ecol. 1985;54:721-38.

24. Park KJ, Jones G, Ransome RD. Torpor, arousal and activity of hibernating greater horseshoe bats (Rhinolophus ferrumequinum). Funct Ecol. 2000;14:580-8.

25. Meteyer CU, Buckles EL, Blehert DS, Hicks AC, Green DE, ShearnBochsler $V$, et al. Histopathologic criteria to confirm white-nose syndrome in bats. J Vet Diagnostic Investig. 2009;21:411-4.

26. Lorch JM, Meteyer CU, Behr MJ, Boyles JG, Cryan PM, Hicks AC, et al. Experimental infection of bats with Geomyces destructans causes white-nose syndrome. Nature. 2011;480:376-8.

27. Warnecke L, Turner JM, Bollinger TK, Lorch JM, Misra V, Cryan PM, et al. Inoculation of bats with European Geomyces destructans supports the novel pathogen hypothesis for the origin of white-nose syndrome. Proc Natl Acad Sci USA. 2012;109:6999-7003.

28. Reeder DM, Frank CL, Turner GG, Meteyer CU, Kurta A, Britzke ER, et al. Frequent arousal from hibernation linked to severity of infection and mortality in bats with white-nose syndrome. PLOS ONE. 2012;7:e38920.

29. Verant ML, Meteyer CU, Speakman JR, Cryan PM, Lorch JM, Blehert DS. White-nose syndrome initiates a cascade of physiologic disturbances in the hibernating bat host. BMC Physiol. 2014;14:10.

30. Holliday C. White-nose syndrome disease surveillance and bat population monitoring report. 2012. Available from: http://www.tnbwg.org/ 2012 White Nose Syndrome Report.pdf.

31. Bernard RF, McCracken GF. Winter behavior of bats and the progression of white-nose syndrome in the southeastern United States. Ecol Evol. 2017;7:1487-96.

32. Johnson JS, Lacki MJ, Thomas SC, Grider JF. Frequent arousals from winter torpor in Rafinesque's big-eared bat (Corynorhinus rafinesquii). PLOS ONE. 2012;7:e49754.

33. Bernard RF, Willcox EV, Parise KL, Foster JT, McCracken GF. White-nose syndrome fungus, Pseudogymnoascus destructans, on bats captured emerging from caves during winter in the southeastern United States. BMC Zool. 2017;2:12.

34. Clare EL, Fraser EE, Braid HE, Fenton MB, Hebert PDN. Species on the menu of a generalist predator, the eastern red bat (Lasiurus borealis): using a molecular approach to detect arthropod prey. Mol Ecol. 2009;18:2532-42.

35. Clare EL, Symondson WOC, Fenton MB. An inordinate fondness for beetles? Variation in seasonal dietary preferences of night-roosting big brown bats (Eptesicus fuscus). Mol Ecol. 2013;23:3633-47. 
36. Clare EL, Symondson WOC, Broders H, Fabianek F, Fraser EE, MacKenzie A, et al. The diet of Myotis lucifugus across Canada: assessing foraging quality and diet variability. Mol Ecol. 2014;23:3618-32.

37. Van Den Bussche RA, Lee DN, Judkins ME, Dyer JE, Thompson DM, Stark RC, et al. Molecular dietary analysis of the endangered Ozark big-eared bat (Corynorhinus townsendii ingens). Acta Chiropterologica. 2016;18:181-91.

38. Staliński J. Digestion, defecation and food passage rate in the insectivorous bat Myotis myotis. Acta Theriol. 1994;39:1-11.

39. Brown VA, de Torrez EB, McCracken GF. Crop pests eaten by bats in organic pecan orchards. Crop Prot. 2015;67:66-71.

40. U.S. Fish and Wildlife Service. National white-nose syndrome decontamination protocol. 2016. Available from: https://www.whitenosesyndrome. org/sites/default/files/resource/national_wns_decon_protocol_04.12. 2016.pdf.

41. Zeale MRK, Butlin RK, Barker GL, Lees DC, Jones G. Taxon-specific PCR for DNA barcoding arthropod prey in bat faeces. Mol Ecol Resour. 2011;11:236-44.

42. Divoll TJ, Brown VA, Kinne J, McCracken GF, O'Keefe JM. Disparities in second-generation DNA metabarcoding results exposed with accessible and repeatable workflows. Mol Ecol Resour. 2018;18:590-601.

43. Caporaso JG, Kuczynski J, Stombaugh J, Bittinger K, Bushman FD, Costello EK, et al. QIIME allows anlaysis of high-throughput community sequencing data. Nat Methods. 2010;7:335-6.

44. Cravens ZM, Brown VA, Divoll TJ, Boyles JG. Illuminating prey selection in an insectivorous bat community exposed to artificial light at night. J Appl Ecol. 2018:55:705-13.

45. Ratnasingham S, Hebert PDN. BARCODING BOLD: the barcode of life data system. Mol Ecol Notes. 2007;7:355-64.

46. Chamberlain S. bold: interface to bold systems API. 2019. p. 18. Available from: https://cran.r-project.org/web/packages/bold/bold.pdf.

47. R Development Core Team. R: A language and environment for statistical computing. Vienna, Austria: R Foundation for Statistical Computing; 2019.

48. Deagle BE, Thomas AC, McInnes JC, Clarke LJ, Vesterinen EJ, Clare EL, et al. Counting with DNA in metabarcoding studies: how should we convert sequence reads to dietary data? Mol Ecol. 2018;28:391-406.

49. Vesterinen EJ, Lilley TM, Puisto AIE, Blomberg AS, Lilley TM. Table for five, please: dietary partitioning in boreal bats. Evol Ecol. 2018;8:10914-37.

50. Hsieh TC, Ma KH, Chao A. iNEXT: an R package for rarefaction and extrapolation of species diversity (Hill numbers). Methods Ecol Evol. 2016;7:1451-6.

51. Chao A, Jost L. Coverage-based rarefaction and extrapolation: standardizing samples by completeness rather than size. Ecology. 2012;93:2533-47.

52. Chao A, Chiu C-H, Jost L. Unifying species diversity, phylogenetic diversity, functional diversity, and related similarity and differentiation measures through Hill numbers. Annu Rev Ecol Evol Syst. 2014:45:297-324.

53. Cohen Y, Bar-David S, Nielsen M, Bohmann K, Korine C. An appetite for pests: synanthropic insectivorous bats exploit cotton pest irruptions and consume various deleterious arthropods. Mol Ecol. 2020;29:1185-98.

54. Oksanen J, Blanchet FG, Friendly M, Kindt R, Legendre P, Mcglinn D, et al. Package "vegan." Community Ecol Packag. 2019;29:1-297.

55. Anderson MJ, Walsh DCI. PERMANOVA, ANOSIM, and the Mantel test in the face of heterogeneous dispersions: what null hypothesis are you testing? Ecol Monogr. 2013;83:557-74.

56. Dormann C, Gruber B, Fründ J. Introducing the bipartite package: analysing ecological networks. Interaction. 2008;8:8-11.

57. Krauel JJ, Brown VA, Westbrook JK, McCracken GF. Predator-prey interaction reveals local effects of high-altitude insect migration. Oecologia. 2018;186:49-58

58. Kolkert H, Andrew R, Smith R, Rader R, Reid N. Insectivorous bats selectively source moths and eat mostly pest insects on dryland and irrigated cotton farms. Ecol Evol. 2019;10:371-88.

59. Gregory BB, Whitaker JO, Hartman GD. Diet of Rafinesque's big-eared bat (Corynorhinus rafinesquii) in West-Central Louisiana. Southeast Nat. 2014;13:762-9.

60. Lacki MJ, Ladeur KM. Seasonal use of lepidopteran prey by Rafinesque's big-eared bats (Corynorhinus rafinesquii). Am Midl Nat. 2001;145:213-7.
61. Johnson JS, Lacki MJ, Fulton SA. Foraging patterns of Rafinesque's big-eared bat in upland forests managed with prescribed fire. J Mamm. 2019:100:500-9.

62. Lacki MJ, Amelon SK, Baker MD. Foraging ecology of bats in forests. In: Lacki MJ, Hayes JP, Kurta A, editors. Bats for conserv manag. Baltimore: The Johns Hopkins University Press; 2007. p. 83-127.

63. Lacki MJ, Dodd LE. Diet and foraging behavior of Corynorhinus in eastern North America. In: Loeb SC, Lacki MJ, Miller DA, editors. Conservation and Management of big-eared bats A Symposium. Asheville: US Department of Agriculture Forest Service; 2011. p. 39-52.

64. Wray AK, Peery MZ, Jusino MA, Kochanski JM, Banik MT, Palmer JM, et al. Predator preferences shape the diets of arthropodivorous bats more than quantitative local prey abundance. Mol Ecol. 2021;30:855-73.

65. Gore JA. Gray bat, Myotis grisescens. In: Humphrey SR, editor. Rare Endanger biota Florida Vol 1 Mamm. Gainesville: University Press of Florida; 1992. p. 63-70.

66. Thomson CE. Myotis sodalis. Mamm Species. 1982;1-5.

67. Murray SW, Kurta A. Nocturnal activity of the endangered Indiana bat (Myotis sodalis). J Zool. 2004;262:197-206.

68. Murray SW, Kurta A. Spatial and temporal variation in diet. Indiana Bat Biol Manag an endagered species. 1998. p. 182-92.

69. Kurta A, Whitaker JO, Whitaker JO Jr. Diet of the endangered Indiana Bat (Myotis sodalis) on the northern edge of its range. Am Midl Nat. 1998:140:280-6.

70. Tuttle NM, Benson DP, Sparks DW. Diet of the Myotis sodalis (Indiana Bat) at an Urban/Rural Interface. Northeast Nat. 2006;13:435-42.

71. Brack V Jr, Laval RK. Diet of the gray myotis (Myotis grisescens): variability and consistency, opportunism, and selectivity. J Mamm. 2006;87:7-18.

72. Hoffman R. Spiders of the family Anyphaenidae in Virginia (Arachnida: Araneida). Banisteria. 2002;19:9-12.

73. Bradley RA. Common spiders of North America. Berkley: University of Ca; 2013.

74. Maucieri DG, Barclay RMR. Consumption of spiders by the little brown bat (Myotis lucifugus) and the long-eared bat (Myotis evotis) in the Rocky Mountains of Alberta. Can J Zool. 2020;99:221-6.

75. Agosta SJ, Morton D. Diet of the big brown bat, Eptesicus fuscus, from Pennsylvania and Western Maryland. Northeast Nat. 2003;10:89.

76. Whitaker JO, Barnard SM. Food of big brown bats (Eptesicus fuscus) from a colony at Morrow. Georgia Southeast Nat. 2005;4:111-8.

77. Battisti A, Stastny M, Netherer S, Robinet C, Schopf A, Roques A, et al. Expansion of geographic range in the pine processionary moth caused by increased winter temperatures. Ecol Appl. 2005;15:2084-96.

78. Bale JS, Masters GJ, Hodkinson ID, Awmack C, Bezemer TM, Brown VK, et al. Herbivory in global climate change research: direct effects of rising temperature on insect herbivores. Glob Chang Biol. 2002;8:1-16.

79. Bale JS, Hayward SAL. Insect overwintering in a changing climate. J Exp Biol. 2010;213:980-94.

80. Kaňuch P, Janečková K, Krištín A. Winter diet of the noctule bat Nyctalus noctula. Folia Zool. 2005;54:53-60.

81. Williams C, Salter L, Jones G. The winter diet of the lesser horseshoe bat (Rhinolophus hipposideros) in Britain and Ireland. Hystrix It J Mamm. 2011;22:159-66.

82. Whitaker $\mathrm{JO} \mathrm{Jr}$, Rissler $\mathrm{L}$. Winter activity of bats at a mine entrance in Vermillion County. Indiana Am Midl Nat. 1992;127:52-9.

83. Dunbar MB, Brigham RM. Thermoregulatory variation among populations of bats along a latitudinal gradient. J Comp Physiol B. 2010;180:885-93.

84. Sherwin HA, Montgomery WI, Lundy MG. The impact and implications of climate change for bats. Mamm Rev. 2013;43:171-82.

85. Reusch C, Gampe J, Scheuerlein A, Meier F, Grosche L, Kerth G. Differences in seasonal survival suggest species-specific reactions to climate change in two sympatric bat species. Ecol Evol. 2019;9:7957-65.

\section{Publisher's Note}

Springer Nature remains neutral with regard to jurisdictional claims in published maps and institutional affiliations. 